\title{
Steroid-Induced Hyperglycemia Successfully Treated With Once-Weekly Dulaglutide in an Old Patient With Type 2 Diabetes
}

\author{
Hidetaka Hamasaki ${ }^{a}$, b, c , Shingo Morimitsu ${ }^{\mathrm{b}}$
}

\begin{abstract}
Glucocorticoids induce hyperglycemia in case of pancreatic $\alpha$ - and $\beta$-cell dysfunction. Glucagon-like peptide-1 receptor agonists (GLP1RA) may prevent steroid-induced hyperglycemia by improving hyperglucagonemia and insulin secretion. An 85-year-old man was treated with oral prednisolone for chronic hypersensitivity pneumonitis, and his glycemic control deteriorated after the initiation of steroid therapy. After the administration of dulaglutide injection, his glycemic control was improved and we could discontinue insulin therapy. Both fasting and postprandial plasma glucagon levels were significantly suppressed by a GLP-1RA, dulaglutide. GLP-1RAs therapy may be a useful strategy for the treatment of steroid-induced hyperglycemia.
\end{abstract}

Keywords: Glucocorticoids; Glucagon-like peptide-1 receptor agonists; Glucagon; Insulin; Type 2 diabetes

\section{Introduction}

Glucocorticoids induce hyperglycemia in case of $\alpha$ - and $\beta$-cell dysfunction, insulin resistance, and decreased glucose uptake in skeletal muscle [1,2]. Van Raalte et al [3] have reported that the glucagon-like peptide-1 receptor agonist (GLP-1RA), exenatide, prevents oral prednisolone-induced hyperglycemia by improving hyperglucagonemia and insulin secretion in healthy men. Ohashi et al [4] have also shown that a dipeptidyl peptidase-4 (DPP-4) inhibitor improves steroid-induced hyperglycemia by decreasing plasma glucagon levels in patients with chronic kidney disease. DPP-4 inhibitors may be safe and effective for steroid-induced hyperglycemia [5]. However, the effect of GLP-1RAs on steroid-induced hyperglycemia in patients with diabetes is not yet fully investigated. We have reported a case of patients with type 2 diabetes whose glycemic

Manuscript submitted February 5, 2018, accepted February 21, 2018

${ }^{a}$ Hamasaki Clinic, Kagoshima, Japan

bepartment of Diabetes, Imakiire General Hospital, Kagoshima, Japan ${ }^{\mathrm{c} C o r r e s p o n d i n g ~ A u t h o r t: ~ H i d e t a k a ~ H a m a s a k i, ~ H a m a s a k i ~ C l i n i c, ~ 2-21-4 ~ N i-~}$ shida, Kagoshima 890-0046, Japan. Email: hhamasaki78@gmail.com

doi: https://doi.org/10.14740/jem491w control was improved due to reduction in glucagon levels by the administration of once-weekly GLP-1RA, dulaglutide [6]. Here we report a case of steroid-induced hyperglycemia successfully treated with dulaglutide.

\section{Case Report}

An 85-year-old man admitted to our hospital presented with dyspnea. His height and weight were $150.5 \mathrm{~cm}$ and $52.5 \mathrm{~kg}$, respectively. He was diagnosed as having chronic hypersensitivity pneumonitis, and treatment with $25 \mathrm{mg}$ of oral prednisolone was started. He also suffered from untreated type 2 diabetes and chronic kidney failure. His plasma glucose and hemoglobin A1c levels were $117 \mathrm{mg} / \mathrm{dL}$ and $7.0 \%$, respectively, on admission. His serum creatinine levels were elevated to $2.24 \mathrm{mg} / \mathrm{dL}$, and his estimated glomerular filtration rate was decreased to $22.4 \mathrm{~mL} / \mathrm{min} / 1.73 \mathrm{~m}^{2}$. Diet therapy $(1,400$ $\mathrm{kcal} /$ day; $62 \%$ carbohydrate, $12 \%$ protein, and $26 \%$ fat) was commenced; however, glycemic control deteriorated after the initiation of steroid therapy. We started insulin therapy using human insulin. As a result of using 6, 12, and 10 units of insulin before breakfast, lunch, and dinner, respectively, his blood glucose levels were $120-180 \mathrm{mg} / \mathrm{dL}$. We measured his plasma glucose, serum C-peptide (E-test TOSOH II; Tosoh, Tokyo, Japan), and plasma glucagon (Glucagon ELISA; Cosmic, Tokyo, Japan) [7] levels before and $2 \mathrm{~h}$ after breakfast to investigate the role of $\alpha$ - and $\beta$ - cells (Fig. 1a). The dosage of prednisolone was reduced to $15 \mathrm{mg}$ /day due to the improvement of chronic hypersensitivity pneumonitis. Although his glycemic control was stable, insulin self-injections were discontinued because of cognitive decline. Therefore, we added a once-weekly dulaglutide injection and mitiglinide to the insulin therapy. After the administration of dulaglutide injection, the total insulin dosage was significantly decreased from 22 units/day to 9 units/day. We added mitiglinide 2 days after dulaglutide administration, and the insulin dosage was eventually tapered to 0 unit. His blood glucose levels were $80-200$ $\mathrm{mg} / \mathrm{dL}$ when he was using $0.75 \mathrm{mg} /$ week of dulaglutide and $20 \mathrm{mg} /$ day of mitiglinide. He did not experience any adverse effects such as nausea and loss of appetite during hospitalization. We remeasured his plasma glucose, serum C-peptide, and plasma glucagon levels before discharge (Fig. 1b). Both fasting and postprandial plasma glucagon levels were reduced, and steroid-induced hyperglycemia was significantly 
a
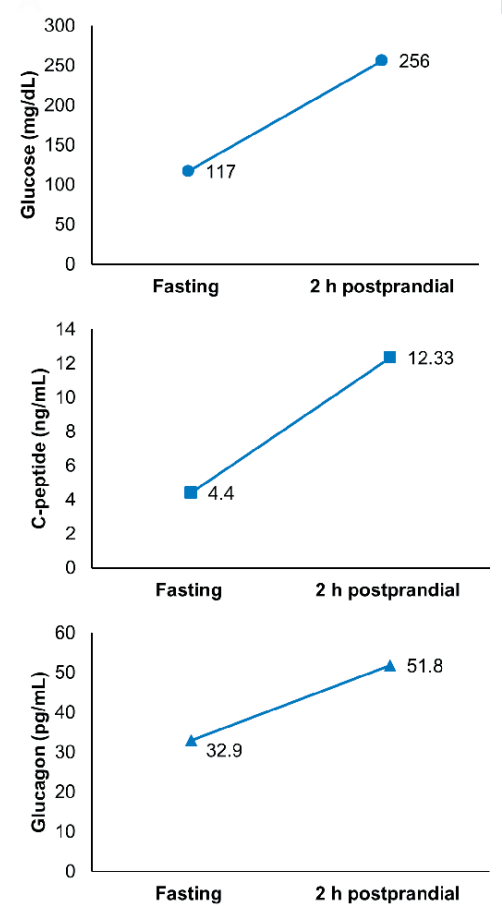

b
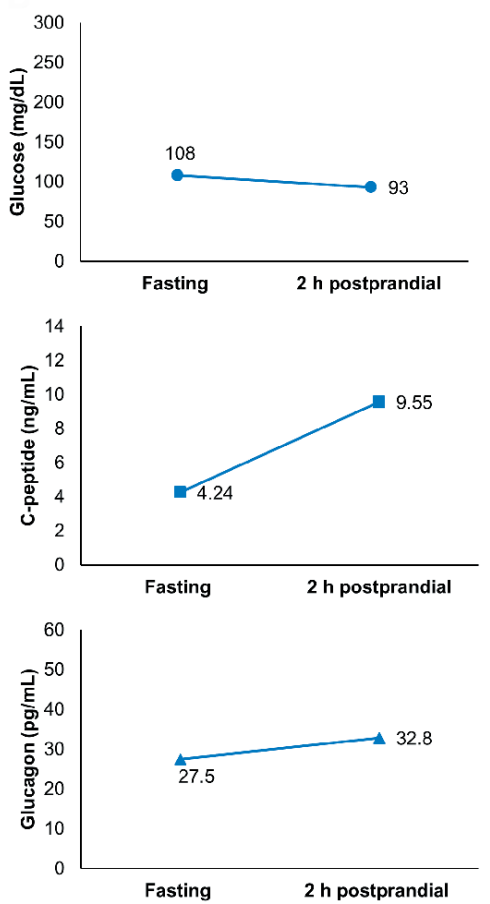

Figure 1. (a) Fasting and $2 \mathrm{~h}$ postprandial levels of glucose, C-peptide, and glucagon during insulin therapy. (b) Fasting and $2 \mathrm{~h}$ postprandial levels of glucose, C-peptide, and glucagon after switching from insulin to dulaglutide.

ameliorated.

\section{Discussion}

GLP-1RAs suppress glucagon secretion, promotes insulin secretion and glucose uptake in muscle, while counteracting the unfavorable effect of glucocorticoids on glucose metabolism [8]. The half-life of dulaglutide is approximately $90 \mathrm{~h}$ in healthy subjects [9], which may also contribute to the improvement of glycemic control in patients treated with oral steroids. Although the dose reduction of prednisolone and improvement of pneumonitis may also have an impact on glycemic control, it is notable that this case shows successful withdrawal of insulin therapy by the administration of dulaglutide. Since serum C-reactive protein levels were decreased to within the normal range when we performed the first measurement of C-peptide and glucagon levels, inflammation was not associated with glycemic control. Steroid-induced hyperglycemia may be ameliorated by the suppression of glucagon secretion. Whether a GLP-1RA is suitable for this patient is up for debate. In general, GLP-1RAs are used in obese patients with type 2 diabetes. Insulin therapy should be continued to safely maintain optimal glycemic control in nonobese patients with renal impairment. However, considering that he suffered from dementia, the administration of a onceweekly dulaglutide injection may be a useful option. To our knowledge, this is the first report of a patient with type 2 diabetes being successfully treated for steroid-induced hyperglycemia using dulaglutide. GLP-1RA therapy should be explored as a potential strategy for the treatment of steroid-induced hyperglycemia. To elucidate the underlying mechanism, further research will be required.

\section{Author Contributions}

S.M. and H.H. equally contributed to this work.

\section{Competing of Interest}

The authors declare that they have no competing interests.

\section{References}

1. Hwang JL, Weiss RE. Steroid-induced diabetes: a clinical and molecular approach to understanding and treatment. Diabetes Metab Res Rev. 2014;30(2):96-102.

2. Rafacho A, Goncalves-Neto LM, Santos-Silva JC, Alonso-Magdalena P, Merino B, Taboga SR, Carneiro EM, et al. Pancreatic alpha-cell dysfunction contributes to the disruption of glucose homeostasis and compensatory insulin hypersecretion in glucocorticoid-treated rats. PLoS One. 2014;9(4):e93531.

3. van Raalte DH, van Genugten RE, Linssen MM, Ouwens DM, Diamant M. Glucagon-like peptide-1 receptor agonist treatment prevents glucocorticoid-induced glucose 
intolerance and islet-cell dysfunction in humans. Diabetes Care. 2011;34(2):412-417.

4. Ohashi N, Tsuji N, Naito Y, Iwakura T, Isobe S, Ono M, Fujikura $\mathrm{T}$, et al. Alogliptin improves steroid-induced hyperglycemia in treatment-naive Japanese patients with chronic kidney disease by decrease of plasma glucagon levels. Med Sci Monit. 2014;20:587-593.

5. Yanai H, Masui Y, Yoshikawa R, Kunimatsu J, Kaneko H. Dipeptidyl peptidase-4 inhibitor for steroid-induced diabetes. World J Diabetes. 2010;1(3):99-100.

6. Morimitsu S, Hamasaki H. Improved glycemic control due to reduction in glucagon levels by the administration of once-weekly dulaglutide in a non-obese patient with type 2 diabetes. J Endocrinol Metab. 2018;8(1)6-9.

7. Sloan JH, Siegel RW, Ivanova-Cox YT, Watson DE, Deeg MA, Konrad RJ. A novel high-sensitivity electrochemiluminescence (ECL) sandwich immunoassay for the specific quantitative measurement of plasma glucagon. Clin Biochem. 2012;45(18):1640-1644.

8. Drucker DJ. The role of gut hormones in glucose homeostasis. J Clin Invest. 2007;117(1):24-32.

9. Barrington P, Chien JY, Tibaldi F, Showalter HD, Schneck K, Ellis B. LY2189265, a long-acting glucagon-like peptide-1 analogue, showed a dose-dependent effect on insulin secretion in healthy subjects. Diabetes Obes Metab. 2011;13(5):434-438. 